Sitzungsberichte des Plenums und der problemgebundenen Klassen der Deutschen Akademie der Wissenschaften zu Berlin

\title{
Werner Bahner
}

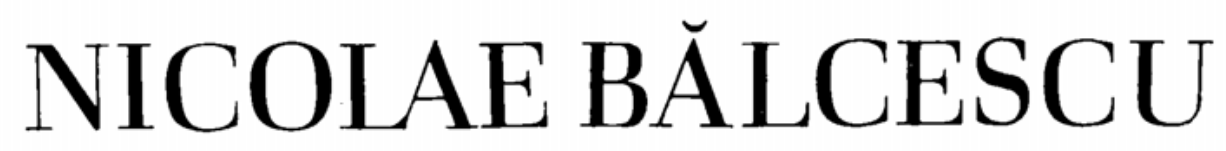

(1819-1852)

Ein rumänischer revolutionärer

Demokrat im Kampf

für soziale und nationale Befreiung 

Sitzungsberichte des Plenums und der problemgebundenen Klassen der Deutschen Akademie der Wissenschaften zu Berlin

Werner Bahner

NICOLAE BĂLCESCU $(1819-1852)$

Ein rumänischer revolutionärer

Demokrat im Kampf

für soziale und nationale Befreiung

AKADEMIE - VERLAG - BERLIN 1970 
Vortrag gehalten von Herrn Werner Bahner

in der Feierstunde der Deutschen Akademie

der Wissenschaften zu Berlin

und der Kommission für UNESCO-Arbeit

der Deutschen Demokratischen Republik

zu Ehren des 150. Geburtstages

des rumänischen Historikers und Schriftstellers Nicolae Bălcescu

am 30. Oktober 1969

Herausgegeben im Auftrage

des Präsidenten der Deutschen Akademie

der Wissenschaften zu Berlin

von Vizepräsident Prof. Dr. Werner Hartke

Erschienen im Akademie-Verlag GmbH, 108 Berlin, Leipziger Str. 3-4

Copyright 1970 by Akademie-Verlag GmbH

Lizenznummer: $202 \cdot 100 / 257 / 70$

Herstellung: IV/2/14 VEB Werkdruck, 445 Gräfenhainichen $\cdot 3451$

Bestellnummer: 2010/70/V/1 - ES $7 \mathrm{H}$

EDV-Nr.: 7518229

4;50 